\title{
Effects of salmon lice infection on the behaviour of sea trout in the marine phase
}

\author{
Karl Øystein Gjelland ${ }^{1, *}$, Rosa Maria Serra-Llinares ${ }^{2}$, Richard David Hedger $^{3}$, \\ Pablo Arechavala-Lopez ${ }^{2,3,4}$, Rune Nilsen ${ }^{2}$, Bengt Finstad $^{3}$, Ingebrigt Uglem ${ }^{3}$, \\ Ove Tommy Skilbrei ${ }^{2}$, Pål Arne Bjørn²
}

\author{
${ }^{1}$ Norwegian Institute for Nature Research, the Fram Centre, 9296 Tromsø, Norway \\ ${ }^{2}$ Institute of Marine Research, 58171 Bergen, Norway \\ ${ }^{3}$ Norwegian Institute for Nature Research, 7485 Trondheim, Norway \\ ${ }^{4}$ Department of Marine Science and Applied Biology, University of Alicante, 03080 Alicante, Spain
}

\begin{abstract}
Salmon lice Lepeophtheirus salmonis Krøyer may affect survival and growth of anadromous salmonids through physiological stress and/or behavioural changes. Using acoustic telemetry tracking, we investigated the behaviour of 30 infected sea trout Salmo trutta throughout the summer in a fjord with very high salmon lice infection pressure. Most of the tracked sea trout adopted a movement pattern expected to suppress salmon lice infestation, as they showed a strong preference for fresh or brackish water, spending most of the time close to a river outlet or even migrating into the river. Highly infested sea trout preferred shallower depths, associated with lower salinity. The fish lost to predation stayed further away from the river outlet than nonpredated fish, and were likely subjected to a stronger infection pressure. Half of the tracked group were treated with a salmon lice prophylaxis, emamectin benzoate. The effect of treatment on infestation was monitored in a separate group held in a sea cage and found to be moderate; the mortality in this group was associated with infestation by motile lice stages. In contrast, treatment was not found to have an effect on tracked fish behaviour. It is likely that some physiological and behavioural responses to high salmon lice infection pressure may be present even after a prophylaxis treatment, in particular when the treatment is given after exposure to salmon lice infection. We conclude that increased salmon lice infection pressure associated with altered salmon farming practice may have the potential to influence the marine behaviour and growth of sea trout.
\end{abstract}

KEY WORDS: Lepeoptheirus salmonis - Sea lice · Anadromy · Host-parasite interactions · Emamectin benzoate $\cdot$ Behavior $\cdot$ Tracking $\cdot$ Telemetry

\section{INTRODUCTION}

Resources are heterogeneously distributed in nature, and many animals may breed in some areas but move to other areas to forage. In some cases these animal movements may be obligate migrations, such as for Atlantic salmon Salmo salar L. In other cases the migration may be facultative, as is the anadromous behaviour of brown trout Salmo trutta L. Brown trout must reproduce in freshwater, and may fulfil all

\footnotetext{
*Corresponding author: karl.gjelland@nina.no
}

parts of its life cycle in freshwater. However, where brown trout has access to the sea, it may smoltify at a size of 12 to $25 \mathrm{~cm}$ and make marine foraging migrations during late spring and summer to enhance growth and reproductive potential (Elliott 1994). This phenotype is referred to as sea trout. The survival and growth at sea are key parameters in understanding population dynamics in anadromous salmonids (Elliott 1994, Aas et al. 2011). Although the sea migration may be rewarding, it also involves

() The authors 2014. Open Access under Creative Commons by Attribution Licence. Use, distribution and reproduction are unrestricted. Authors and original publication must be credited. 
increased predation risk and infection risk by parasites and pathogens. Changes in infection pressure may be brought about by human activities, such as the rapid growth of the salmon farming industry in recent decades (Krkošek et al. 2011, Serra-Llinares et al. 2014). Mapping the individual behaviour of brown trout at sea is therefore essential in describing host-parasite interactions and behavioural responses to changes in infection pressure, and may provide links between activities in the aquaculture industry and the population dynamics of wild sea trout. However, there is currently little detailed information on the behaviour of sea trout in the marine phase.

The salmon louse Lepeophtheirus salmonis Krøyer is a marine ectoparasite of salmonids. It belongs to the subclass Copepoda and has 8 developmental stages: 2 naupliar stages which disperse by drift, an infective free-swimming copepodite stage, 2 attached chalimus stages, 2 preadult stages, and the mature and reproductive stage (Heuch et al. 2000, Boxaspen 2006, Hamre et al. 2013). The louse is motile on the host in the preadult and mature stages. The infective stages feed on the skin, subcutaneous tissue, mucus and plasma of their hosts. Salmon lice occur naturally in cold temperate waters in the northern hemisphere (Boxaspen 2006), but due to the growing salmon fish farming industry, lice densities in coastal waters have increased dramatically (Bjørn et al. 2001, Finstad \& Bjørn 2011, Serra-Llinares et al. 2014). This in turn has increased infection pressure on sea trout, and may have contributed to the recent decline in sea trout populations along the Norwegian coast (Anonymous 2009, Finstad et al. 2011).

Salmon lice infestation causes osmoregulatory stress to the host, resulting in changed levels of haematological parameters, reduced appetite, growth and food conversion efficiency (Boxaspen 2006, Costello 2006). This may affect their host's survival directly as a consequence of lost physiological functionality, or indirectly through added effects of secondary viral and bacterial pathogens (Bjørn et al. 2001, Fast et al. 2006) and/or altered host behaviour (Krkošek et al. 2011). As indicated by experimental work, farm experience and surveys of patterns across populations, more than 5 to 10 lice per fish $(>0.1$ lice $\mathrm{g}^{-1}$ ) can or will become pathogenic (Costello 2006, Wagner et al. 2008).

It is likely that salmonids through natural selection have developed behavioural adaptations in order to avoid or reduce lice infestation (Gjerde et al. 2011). The facultative anadromous migration of sea trout implies that the length of the marine phase may be influenced by the rewards and risks associated with this life history choice. Salmon lice survival decreases with decreasing salinity (Connors et al. 2008), and salmon lice may actively avoid waters with salinity <20 ppt (Heuch 1995). Hence, sea trout have the potential to reduce or rid themselves of infestation by seeking low-salinity waters, such as estuarine surface waters or river water. The term 'premature return' has been coined for a sea trout returning to freshwater at an earlier time than expected if it was not infected (Birkeland 1996, Wells et al. 2007). A premature return is costly for the sea trout as it reduces growth and reproductive potential (Birkeland 1996, Wells et al. 2007, Fjørtoft et al. 2014). Reduced growth furthermore increases predation risk, as it extends the time a fish is vulnerable to size-dependent predation (Werner \& Gilliam 1984). Reduced growth has been shown to be associated with reduced marine survival in sea trout (Jonsson \& Jonsson 2009). Although several works have focused on sea trout premature returns to freshwater as a response to salmon lice infection, little has been done to investigate the behavioural responses while at sea. Given the importance of sea trout behaviour in mitigating the effects of salmon lice, further research on migration patterns at sea is required.

In the present study, we examined the behaviour of sea trout with varying degrees of salmon lice infestation. The movements of sea trout examined for infestation level and tagged with acoustic transmitters were monitored in a receiver array covering both marine and freshwater habitats. Half of the experimental group were treated with a pharmaceutical prophylaxis designed to reduce salmon lice infestation. The infestation development in prophylaxistreated and untreated fish was quantified in a separate net cage experiment. It was hypothesized that (1) high salmon lice infestation would influence the movement pattern of the fish in terms of distance to river outlet and swimming depth, (2) untreated fish would use freshwater and/or low-saline habitats more than treated fish and (3) untreated fish would have a higher mortality rate than treated fish. To inform the reader on the salmon lice infection pressure in the study area, we also report infection control measures obtained from the Norwegian National Salmon Lice Monitoring Program. The infestation pressure was expected to be high during the study, as a consequence of high salmon biomass in the closest fish farms resulting from a new rollover regime among aquaculture production zones in the study system (Serra-Llinares et al. 2014). 


\section{MATERIALS AND METHODS}

\section{Study area}

The study was performed in the Etnefjord, southwestern Norway $\left(59.65^{\circ} \mathrm{N}, 5.88^{\circ} \mathrm{E}\right)$. The area covered by the tracking experiment included the Etnefjord (length $=8.1 \mathrm{~km}$, max. depth $>150 \mathrm{~m}$ ), Ølsfjord and Romsasund, and the Etne River (Fig. 1). The Etne River is the largest river discharging into this fjord system; no other rivers have a large effect on the residual flow. Etnefjord in turn discharges into the Hardangefjord through the Romsasund. The total river stretch available for anadromous salmonids in the Etne River is $13 \mathrm{~km}$, including tributaries. In the June-August period the mean river temperature normally varies between 13 and $16^{\circ} \mathrm{C}$, and the sea surface temperature in the Etnefjord between 15 and $18^{\circ} \mathrm{C}$ (Fjørtoft et al. 2014). Etnefjord is a protected area, in which no fish farming activities are allowed (Serra-Llinares et al. 2014). However, the infection pressure from salmon lice copepodites may be high, due to the spread from other intensively farmed areas in the Hardanger fjord system (Serra-Llinares et al. 2014), through periodical pulses of inflowing waters in the upper water column (Asplin et al. 2011, 2014).

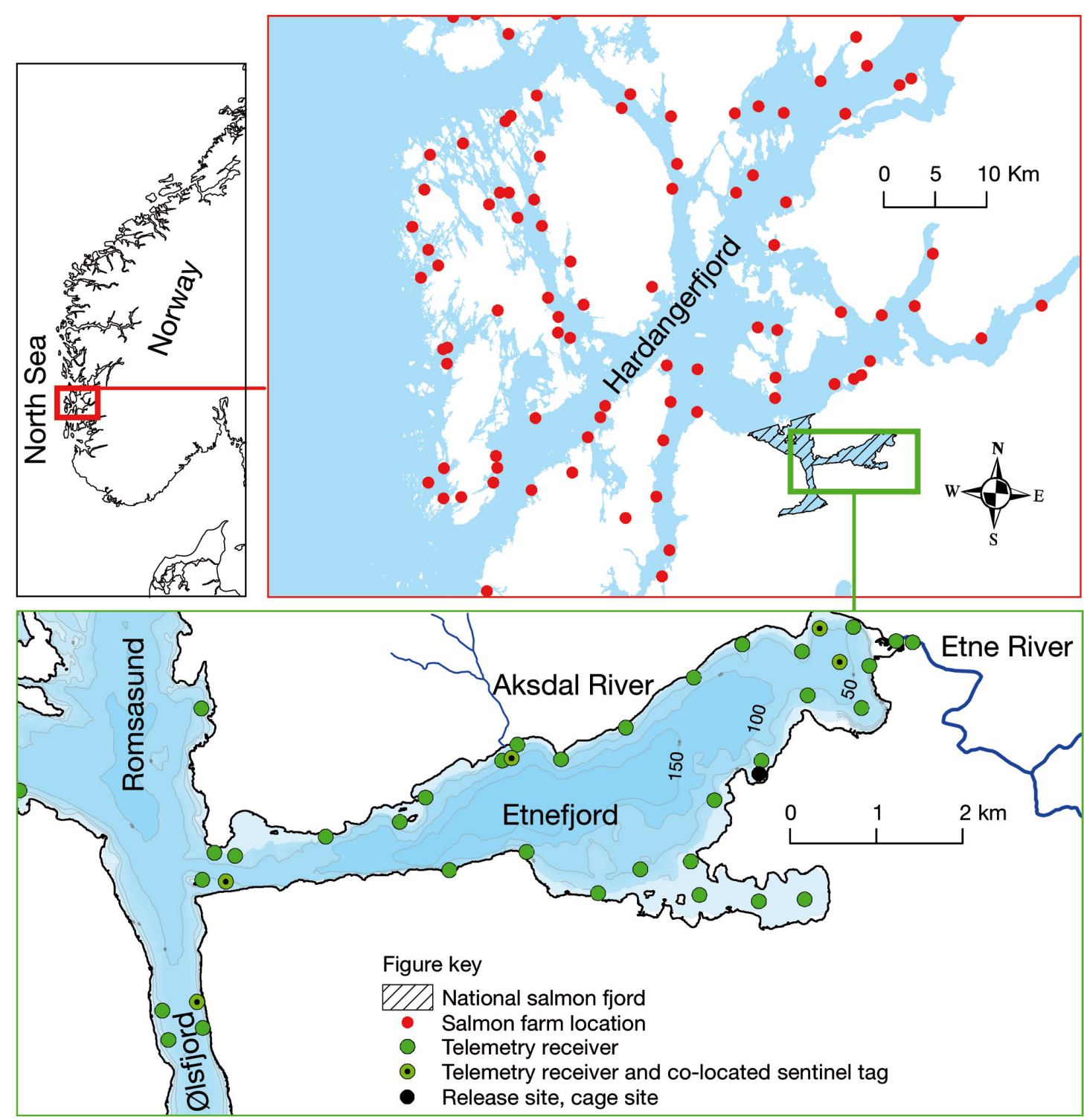

Fig. 1. Study area, showing the Hardangerfjord and Etnefjord and relevant features as indicated by the figure key. One telemetry receiver was also deployed in each of 2 lakes upstream of each Etne River fork (not shown). The shades of blue in the lower map frame show the fjord bathymetry $(50,100$ and $150 \mathrm{~m}$ isoclines are indicated) 


\section{The National Salmon Lice Monitoring Program}

The development of salmon lice Lepeophtheirus salmonis Krøyer infection on sea trout Salmo trutta L. was monitored in the National Salmon Lice Monitoring Program (Bjørn et al. 2012, Serra-Llinares et al. 2014). In this program, sea trout were caught with fyke nets on a daily basis over a period of $6 \mathrm{wk}$, the individual infestation of salmon lice registered, and the fish released back to the sea. The fyke net locations were $0.5,2,6$ and $7 \mathrm{~km}$ from the Etne River outlet. Infestation levels in terms of prevalence, mean individual intensity and mass-specific intensity, as well as the percentage of sea trout with a massspecific intensity above 0.1 lice $\mathrm{g}^{-1}$, were summarized on a weekly basis (Bjørn et al. 2012).

\section{Cage experiment}

Emamectin benzoate (EB) is a widely used prophylaxis in the salmon farming industry. It is absorbed into tissue through feed or by intraperitoneal injection, and kills the parasite via disrupting neurotransmission mechanisms (Glover et al. 2010, Burka et al. 2012). At the end of June 2012, the posttreatment infection development was studied on 20 individually marked sea trout kept in a sea cage ( $2 \mathrm{~m}$ in diameter, $1.5 \mathrm{~m}$ deep) for $8 \mathrm{~d}$ after capture (summary statistics for the cage experiment fish are presented in Table 1; the cage location is shown in Fig. 1). At the start of the experiment, the fish were anaesthetized and marked with T-bars under the dorsal fin. The salmon lice infestation for each individual was recorded according to the count of salmon lice at each of the developmental stages copepodite, chalimus, preadult, adult male and adult female. EB treatment administered by intra-peritoneal injection

Table 1. Characteristics of sea trout individuals in the cage experiment: mean length, body mass and condition factor $(K)$, and median individual intensity (total salmon lice infestation) and individual mass-specific lice intensity (MSI). Values in parentheses show ranges. All values are from the start of the experiment. See Fig. 2 and 'Materials and methods' for treatment description

\begin{tabular}{|c|c|c|}
\hline Parameter & Control $(n=10)$ & Treated $(n=10)$ \\
\hline Length (cm) & $17.4(15.8-19.5)$ & $17.5(15.7-20.0)$ \\
\hline Body mass (g) & $55(42-76)$ & $57(40-74)$ \\
\hline$K$ & $1.04(0.93-1.16)$ & $1.06(0.93-1.21)$ \\
\hline Intensity (lice fish ${ }^{-1}$ ) & $55.5(26-122)$ & $63(11-265)$ \\
\hline MSI (lice $\mathrm{g}^{-1}$ ) & $1.10(0.54-2.26)$ & $1.13(0.28-3.58)$ \\
\hline
\end{tabular}

(see Glover et al. 2010) was given to 10 randomly chosen fish. The remaining 10 fish were administered placebo injections. The dose was $400 \mu \mathrm{g}$ EB $\mathrm{kg}^{-1}$ fish. Expected elimination half-life was $\sim 11 \mathrm{~d}$, and the assumed duration of the protection was $9 \mathrm{wk}$ (Glover et al. 2010). Pharmaceutical prophylaxis administered by intra-peritoneal injection ensures less variable EB treatment as compared to treatment through feed (Skilbrei et al. 2008, Glover et al. 2010), and thus allows for better control of the individual dose. The fish were treated very carefully in all experimental parts to avoid loss of lice due to mechanical handling effects, and little lice detachment was observed during handling. The number of lice at the experiment start were counted after the marking and EB treatment of fish in order to reduce any effect of handling on the change in numbers from the start to the end of the experiment.

At the end of the experiment, all fish were killed by an overdose of anaesthetic, and the infestation of the different salmon lice stages was counted. The individual total intensity was the sum of these counts on each fish. The intensity of motile lice stages was calculated as the sum of preadult and adult stages. This was of interest since the motile stages are more pathogenic than younger stages (Bjørn \& Finstad 1997, Finstad et al. 2000). The individual infection development from the start to the end of the experiment was calculated assuming an exponential infestation growth rate:

$$
r=t^{-1}\left[\log \left(I_{\text {end }}\right)-\log \left(I_{\text {start }}\right)\right]
$$

where $r$ is the intrinsic rate of infestation increase $\left(\mathrm{d}^{-1}\right), I_{\text {start }}$ and $I_{\text {end }}$ are the total infection at the start and end of the experiment, respectively, and $t$ is the experiment length in number of days. For comparison with earlier studies, the prophylaxis efficacy (Stone et al. 1999, 2000) was calculated based on the percentage of surviving lice on individual hosts in the treatment and control groups:

$$
\begin{aligned}
& \% \text { Efficacy }= \\
& 100 \cdot\left(1-\frac{\text { Mean lice survival on treated individuals }}{\text { Mean lice survival on control individuals }}\right)
\end{aligned}
$$

\section{Tracking experiment}

Acoustic telemetry was used to track the behaviour of treated and untreated groups of sea trout. A total of 41 acoustic receivers were deployed; 2 in lakes feeding the Etne River, 2 in the river near the Etne River outlet, 7 in the inner fjord bay near to the river mouth, 20 in the outer fjord, 4 at the mouth of Etne- 
fjord, 4 in Ølsfjord and 2 in the Romsasund (Fig. 1). The receiver coverage was somewhat higher near the Etne River outlet than in most of the fjord, to ensure a high probability of detecting migration back to the river outlet. The Aksdal river is small compared to the Etne River, contributes little freshwater to the sea, and the lower part is too steep to allow sea trout to ascend. The outlet was, however, also given extra attention with high receiver coverage, to ensure detection of fish possibly staying in the outlet zone (Fig. 1). Five sentinel tags were used to provide information on background noise (Vemco V16, average transmission interval $15 \mathrm{~min}$, see Fig. 1 for locations). The detection rate of sentinel tags in much of Etnefjord were lower during the day than at night. No diurnal pattern was shown in detection rates at the Etnefjord mouth, Romsasund and the Etne River mouth. The duration of signal recording was from the release of trout on June 14 until the removal of the receiver array on September 26, 2012.

Thirty sea trout individuals (means \pm SD: length $266 \pm 32.7 \mathrm{~mm}$, mass $191 \pm 64.7 \mathrm{~g}$ ) were captured at 6 locations within the fjord for the tracking experiment (summary statistics for the individuals are presented in Table 2). Lice infestation was recorded, and half the group were given EB treatment (see description in 'Cage experiment' above for administration details and lice counting procedures). The remaining 15 individuals were given placebo injections and served as a control group. All individuals were tagged with V9P-6L acoustic tags (estimated tag life $=123 \mathrm{~d}$, depth sensor with $22 \mathrm{~cm}$ resolution, minimum, mean and maximum signal interval was 60,100 and $140 \mathrm{~s}$, respectively). Individual detection patterns were examined to identify individual fates. Predation was indicated by a diving pattern that was inconsistent with sea trout behaviour; sea trout typically occupy the upper few meters of the water column with frequent short dives to somewhat greater depths, whereas a predation event was indicated by a sud-

Table 2. Characteristics of sea trout individuals tagged and released in the tracking experiment (see Table 1 for explanation of the measurements). See Fig. 2 and 'Materials and methods' for treatment description

\begin{tabular}{|c|c|c|}
\hline Parameter & Control (n = 15) & Treated $(\mathrm{n}=15)$ \\
\hline Length (cm) & $26.8(22.1-34.8)$ & $26.3(22.4-32.9)$ \\
\hline Body mass (g) & 189 (108-300) & $192(108-370)$ \\
\hline$K$ & $0.99(0.39-1.42)$ & $1.02(0.80-1.21)$ \\
\hline Intensity (lice fish ${ }^{-1}$ ) & $40(3-295)$ & $10(1-80)$ \\
\hline MSI (lice ${ }^{-1}$ ) & $0.30(0.01-1.76)$ & $0.04(0.004-0.22)$ \\
\hline
\end{tabular}

den change in vertical swimming behaviour to include much larger depths (Fig. S1 in the Supplement at www.int-res.com/articles/suppl/q005p221_ supp.pdf). Such predation events were also followed by the tag becoming stationary within a few days, indicating that the tag had gone through the digestive system of the predator and had thereafter been dropped to the bottom. Tag expulsion was indicated by a change from normal vertical swimming activity to a sudden and permanent increase in transmitter depth, immediately followed by the tag becoming stationary as indicated by the tidal signature on the depth recordings. This change occurred within a couple of minutes, and it was unlikely that this could be attributed to other events such as predation or catch by fishing gear. This interpretation was confirmed by the recapture of 2 of the living fish that had expelled their tags (see further below).

The fate of each individual was classified as: (1) river-run, if the final detections were within the river; (2) alive in the sea, if detections indicated normal swimming activity (normal vertical and horizontal movements) in the fjord at the removal of the receiver array; (3) lost to predation, according to the predation event interpretation described above; (4) tag loss, according to the expelled tag interpretation described above; (5) emigrated, if the final detections on the outer receivers in Romsasund; and (6) unknown, if tag detections disappeared within the study area during the study period, without a vertical signature that could be attributed to the other classes. Single transmitter detections occurring more than one day apart from other detections were classified as false detections and removed from the data. The final individual sea trout record was defined as the last transmitter detection before a predation event or a tag loss event, and the last detection for the individuals in the other fate categories. Transmitter detections after this time were removed from the individual detection data before further analyses of sea trout behaviour and mortality.

The spatio-temporal distribution of the tagged individuals was determined by calculating the mean number of fish detected per day per receiver in each region (lakes, Etne River mouth, Inner Fjord, Outer Fjord, Etnefjord mouth, and Romsasund). The probability of detection for acoustic transmissions is heavily influenced by distance to the receiver and by weather conditions (Gjelland \& Hedger 2013). In order to reduce potential bias caused by varying detection probabilities in time or space, we computed daily mean individual position and median depth based on hourly means and medians, respectively, to 
ensure equal weighting of all times of the day. Mean hourly positions of each fish were calculated by averaging the locations of the receivers detecting the transmitter within each hour. The individual mean hourly positions were averaged over $24 \mathrm{~h}$ to obtain the individual mean daily positions. Likewise, individual median daily depth was calculated from individual hourly median depths. The distances to the river outlet were estimated as the distances from the mean positions to the centre of the Etne River outlet. Distances were assigned as positive or negative, depending on whether the fish was detected in the fjord or in the river, respectively. For one fish observed to stay for a long period ( $>1 \mathrm{mo}$ ) very close to the centre of the Aksdal river outlet, distance to the river outlet was set to the distance to Aksdal river outlet when this was $<250 \mathrm{~m}$.

\section{Statistics}

All data treatment and statistical analyses were performed with the $\mathrm{R}$ software ( $\mathrm{R}$ Development Core Team 2013). Analysis of infestation and treatment effects on the probability of survival in the caged fish experiment was done using binomial generalised linear modelling (GLM) (R Developement Core Team 2013). The treatment effect on infestation was tested with a linear model, with the intrinsic rate of infestation growth as the response variable, and treatment and initial weight specific intensity as the predictors. Continuous predictor variables were scaled and centred in order to compare effect sizes between categorical and continuous variables (Schielzeth 2010).

The influence of lice intensity (number of salmon lice on each experiment fish) and treatment (EB versus sham control) on the distance to the river outlet was evaluated by linear mixed effects modelling using the LME-function provided in the 'nlme' package (Pinheiro et al. 2013), specifying individuals as random effects. Autocorrelation was accounted for by assuming a continuous first order autoregressive process for a continuous time covariate, nested within individuals (Pinheiro et al. 2013). When analysing distance to the river outlet as a response variable, the distance variable was log-transformed in order to obtain a normal distribution (prior to logtransformation $394 \mathrm{~m}$ was added to have all observations positive; this was subtracted when backcalculating model coefficients).

The individual daily median depths were nonlinearly related to the distance to the river outlet. The influence of intensity and treatment on median depth was therefore modelled using distance to the river outlet as a covariate in a generalised additive mixed model (GAMM) with thin plate regression splines, using the GAMM-function in the 'mgcv' package (Wood 2011). For the statistical tests of any effect of treatment and/or intensity, the most complex model was tested first. Thereafter, the models were simplified by first removing non-significant interaction effects and then non-significant main predictors. The significance level used was 0.05, and we tested the simpler models against the more complex models with ANOVA to test for a significant difference between models (Crawley 2013, R Development Core Team 2013). When models were significantly different, the model associated with the lowest Akaike's information criterion value was chosen; otherwise the simpler model was chosen. For the statistical tests, we excluded data after 1 August in order to avoid including data too far away in time from the infestation assessment time point. Thus, we analysed 48 days of data after the release, which was within the time period that EB was expected to protect against salmon lice infestation (Skilbrei et al. 2008, Glover et al. 2010). This also ensured a better balance in the data from surviving fish, fish lost to predation, and fish that experienced tag loss.

Treatment effects on mortality rates in the tracking experiment were analysed with a parametric survival regression model in the 'survival' package (Therneau 2013), specifying the last observation date as right-censored data (for the 2 recaptures, the final observation date was specified as the recapture date). Individuals were categorized as 'Survived' if alive at the last observation date, or as 'Predated' (dead) if they were lost to predation by the last observation date. The parametric survival regression was performed with 2 alternatives for the survival function; the first was the simplest model with an assumption of constant mortality rate (exponential distribution), the second was a model using the Weibull distribution which allows the mortality rate to change with time at sea (Therneau 2000, 2013). The daily mortality rate $M$ expressed as percentage per day was then calculated as $M=100 \times$ $\left(1-\mathrm{e}^{-z}\right)$, where $z$ is the instantaneous mortality rate estimated with the survival regression model. Survival analysis was also used to test for difference in the tag loss rate between the treatment groups, using Cox proportional hazard regression with the tag expulsion date coded as an event and testing for statistical significance with a likelihood ratio test (Therneau 2000, 2013). 


\section{RESULTS}

\section{Infestation development in sea trout observed in the monitoring program}

The National Salmon Lice Monitoring Program revealed a rapid development of the prevalence and intensity of salmon lice infection on sea trout in the Etnefjord. From Week 24, the prevalence was 99 to $100 \%$. There was a rapid change from low to heavy infection around Week 23, after which the mean mass-specific intensity was $>1$ lice $\mathrm{g}^{-1}$ (Table 3 ).

\section{Infestation development in caged trout}

All but 2 fish (control) had reduced total intensity at the end of the cage experiment (Fig. 2a), with a mean reduction of $57.6 \%$ and $26.0 \%$ for treatment and control group, respectively (Fig. 2b). Thus, the EB treatment effect was a $31.6 \%$ intensity reduction over the experiment duration of $8 \mathrm{~d}$. The treatment efficacy (sensu Stone et al. 1999, 2000) was $42.7 \%$. The decline in intensity was statistically significant in both groups, and treatment and initial intensity had significant negative effects on infestation growth (model $r \sim$ Treatment + Initial intensity, $\mathrm{p}_{\text {Intercept }}<0.001$, $\mathrm{p}_{\text {Treatment }}<0.001, \mathrm{p}_{\text {Initial intensity }}=0.025$, adj. $\mathrm{R}^{2}=0.58$, interaction term not significant, standardized effect sizes -0.080 and -0.035 , respectively). See Table 1 for summary of initial infestation in the caged sea trout. Chalimus and preadults were the dominant louse developmental stages (Table 4). A recruitment of younger stages into older stages was evident, whereas there was little or no new recruitment of copepodites (193 and 3 copepodites in total at the start and end of the experiment, respectively; for per-

Table 3. Weekly means $( \pm \mathrm{SD})$ and maximums (intensity) and medians (massspecific intensity, MSI) of salmon lice infestation on individual sea trout in the Etnefjord, as monitored by the National Salmon Lice Monitoring Program (Bjørn et al. 2012). Prevalence gives the proportion of sampled individuals that were infected with salmon lice. The percentage of fish that had a mass-specific intensity above the 0.1 lice $\mathrm{g}^{-1}$ threshold is given in the last column

\begin{tabular}{|cccccccc|}
\hline Week & $\mathrm{n}$ & Mass (g) & $\begin{array}{c}\text { Prevalence } \\
(\%)\end{array}$ & $\begin{array}{c}\text { Intensity } \\
\left(\text { lice fish }^{-1}\right)\end{array}$ & $\begin{array}{c}\text { Max. } \\
\left(\text { lice }^{-1}\right)\end{array}$ & $\begin{array}{c}\text { MSI fish with MSI } \\
>0.1 \text { lice }^{-1}\end{array}$ \\
\hline 14 & 29 & $380 \pm 393$ & 44.8 & $13.7 \pm 16.5$ & 63 & 0.000 & 3.45 \\
21 & 130 & $73.9 \pm 125$ & 50.8 & $16.0 \pm 45.9$ & 350 & 0.013 & 13.9 \\
22 & 398 & $524 \pm 634$ & 52.0 & $7.2 \pm 13.4$ & 81 & 0.004 & 16.7 \\
23 & 89 & $99.6 \pm 245$ & 85.4 & $98.2 \pm 106$ & 470 & 0.531 & 77.5 \\
24 & 205 & $104 \pm 225$ & 99.0 & $139 \pm 113$ & 689 & 1.78 & 92.2 \\
25 & 120 & $85.9 \pm 140$ & 100 & $88.4 \pm 96.9$ & 689 & 1.01 & 95.0 \\
26 & 8 & $142 \pm 155$ & 100 & $163 \pm 199$ & 537 & 1.11 & 100 \\
\hline
\end{tabular}
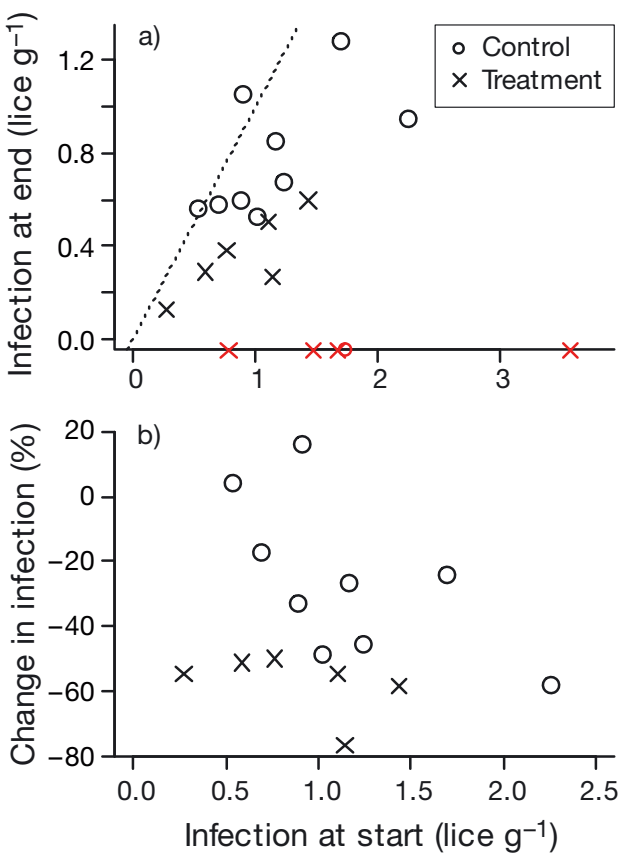

Fig. 2. Mass-specific salmon lice infestation (a) at the start and end of the cage experiment. (b) The relative change in mass-specific infestation during the cage experiment. The infestation of sea trout that died is indicated with red symbols on the $x$-axis in (a). The dotted line indicates unity (same value at end and start). The treatment group received emamectin benzoate (EB) as a prophylaxis against salmon lice infection; the control group received a placebo injection (carrier fluid without EB)

cent contributions, see Table 4). At the end of the experiment, the skin concentration of EB in treatment fish (mean $\pm \mathrm{SD}$ ) was $247 \pm 48 \mu \mathrm{g} \mathrm{kg}^{-1}$ (range: $\left.187-316 \mu \mathrm{gg}^{-1}, \mathrm{n}=5\right)$. For the control fish, the skin concentration was $2.6 \pm 0.9 \mu \mathrm{gg}^{-1}$ (range: $1.6-3.7 \mu \mathrm{g}$ $\left.\mathrm{kg}^{-1}, \mathrm{n}=4\right)$. We do not know if this EB presence in control fish was an analysis artefact or results from contamination in the field, but we consider the levels too low to have had any effect. Five fish died during the experiment ( 1 control and 4 treated fish), all with infestation $>0.75$ lice $\mathrm{g}^{-1}$. Survival was negatively influenced by the intensity of motiles (GLM, model Survival Initial intensity of motiles, $\mathrm{p}_{\text {Intercept }}<0.033$, $\mathrm{p}_{\text {Motiles }}=$ 0.043).

\section{Fate of individuals in the tracking experiment}

In the survival analysis on tracked fish, no statistical effect of 
Table 4. Mean contribution (\%) of the different salmon lice developmental stages to the individual total lice counts in the cage and tracking experiments at the start of the experiment

\begin{tabular}{|lcccccc|}
\hline Experiment & Treatment & Copepodite & Chalimus & Preadult & $\begin{array}{c}\text { Adult } \\
\text { males }\end{array}$ & $\begin{array}{c}\text { Adult } \\
\text { females }\end{array}$ \\
\hline Cage & Control & 7.5 & 52.6 & 38.0 & 1.0 & 0.9 \\
Cage & Vaccine & 13.8 & 43.3 & 35.4 & 1.8 & 5.7 \\
Tracking & Control & 4.54 & 71.34 & 18.30 & 1.73 & 3.93 \\
Tracking & Vaccine & 2.30 & 56.13 & 27.83 & 2.64 & 11.09 \\
\hline
\end{tabular}

Fig. 3. Fate of the tracked sea trout, according to the classification described in 'Materials and methods'. The one individual that lost the tag in the river was classified as both river-run and tag loss, hence the numbers sum to 31 . See Fig. 2 for treatment description treatment or initial intensity (including initial intensity of motiles) was found on the survival (parametric survival regression, starting model Survival $\sim$ Treatment $x$ Intensity), and there was no support for a time-dependent mortality rate (see Table 2 for summary of initial infestation). The study design allowed most transmitters to be tracked throughout the study period, and only 1 fish was classified as having emigrated from the study area. A total of 10 individuals $(33 \%$, control + treated fish) were classified as river-run, 7 (23\%) were classified as alive in sea, and 6 were lost to predation (20\%) (Fig. 3). Six treated individuals experienced tag loss (5 in the fjord and 1 in the river), and the tag loss rate was statistically significantly different between treatment and control groups (Cox proportional hazard regression, $\mathrm{p}=0.002$ ). Two fish (both with tag loss) were recaptured in gillnets in the sea without the tag in September, giving a registered fishing mortality of $6.7 \%$. Thus, at least $56 \%$ of the tagged and released fish were potential survivors, and $27 \%$ suffered mortality in the sea. The estimated constant daily mortality rate was $0.32 \%$ (predation mortality only).

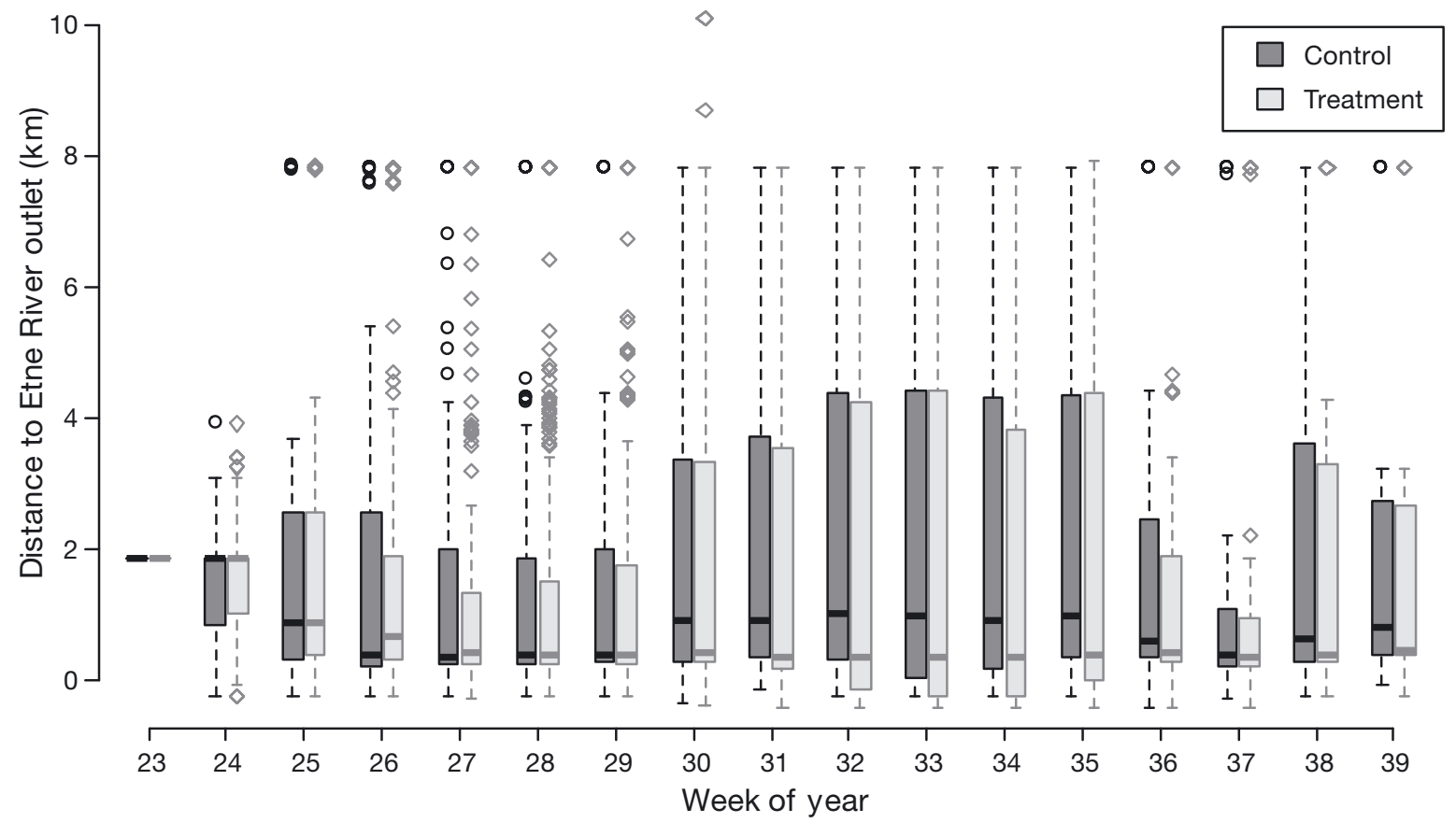

Fig. 4. Tracked sea trout daily individual mean distance to river mouth, averaged over week and summarized by treatment type. The thick line within each box indicates the median distance, the box the interquartile range, the dashed line extending to the whiskers indicates 1.5 times the interquartile range, and diamonds (treatment) and circles (control) the outlier extremes. The horizontal bars in Week 23 indicate the distance from the release site to the river outlet. See Fig. 2 for treatment description 

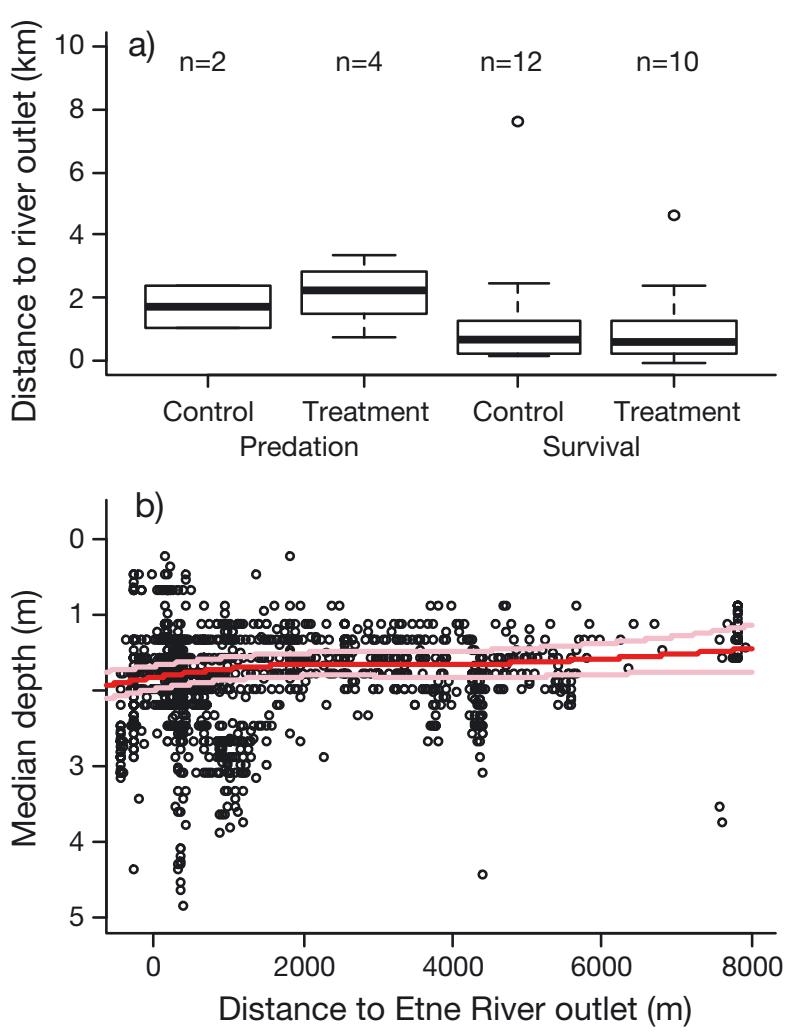

Fig. 5. (a) Individual median daily distance to river outlet in tracked sea trout, grouped by treatment and loss of individuals to predation vs. survival. Individuals that experienced tag loss were grouped with the survivors. See Fig. 2 for treatment description. (b) Individual daily median depths for tracked sea trout plotted against the distance to the Etne River outlet. The red line indicates the generalised additive mixed model fit (see 'Results') with prediction for an individual with a total infection of 40 salmon lice, and the pink lines indicate 2 times the standard error of the prediction

\section{Occupancy patterns within the fjord}

The tagged fish used the inner fjord and Etne River much more than they used the outer fjord. Shortly after their release (14 June, Week 24), the majority moved close to the river outlet or even into the river (Fig. 4). The earliest river return occurred the day after the release (Week 24). Individual daily median distances to the Etne River outlet were generally within $1 \mathrm{~km}$, but the variation and median distance increased in August (Weeks 30-34, Fig. 4). Predation occurred from 365 to $3478 \mathrm{~m}$ from the Etne River outlet, but fish that were lost to predation had spent more time further away from the river outlet than those that survived (Fig. 5a) (LME, model log(Distance) $\sim$ Fate, $\mathrm{p}=0.041$, geometric mean distance for predated fish: $1749 \mathrm{~m}$, geometric mean distance for survivors: $671 \mathrm{~m}$ ). No significant effect of intensity, treatment or fish size on the distance to the river out- let was found, and there was no clear difference in occupancy pattern due to treatment (Fig. 4).

\section{Depth use}

The fish were generally observed closer to the surface far away from the river outlet than in the river and in the vicinity of the river outlet (Fig. 5b), and fish with higher infestation intensity stayed closer to the surface no matter how far from the river outlet they were observed (GAMM, model Median depth $\mathrm{s}($ Distance $)+$ Intensity, $\mathrm{p}_{\mathrm{s} \text { (Distance) }}<0.001, \mathrm{p}_{\text {Intensity }}=$ 0.022). The estimated coefficient for the intensity effect was -0.0029 . Thus, a fish with a total lice intensity of 300 was estimated to stay on average $0.9 \mathrm{~m}$ closer to the surface than a fish with no lice.

\section{DISCUSSION}

This study successfully tracked 30 sea trout caught and released at sea, with a high resolution in time and space. The lice infection pressure was high, associated with high biomass in salmon farms further out in the fjord (Serra-Llinares et al. 2014). We found support for our hypothesis (1) that infestation influences movement patterns, as most fish preferred to be in the proximity of a less saline environment, and swimming depth was negatively correlated with infestation level. However, we did not find support for our hypotheses (2 and 3 ) that prophylaxis treatment would influence the use of low-salinity habitats and mortality, since we found no behavioural association with EB treatment nor any support for lower mortality associated with salmon lice prophylaxis (EB treatment), although EB treatment had a significant effect on infestation development in caged trout. Individuals that suffered predation tended to stay further away from the river outlet than the surviving individuals, indicating that the use of fjord habitats was associated with higher predation risk, and/or that fish that attained higher infestation were more susceptible to predation.

\section{Infestation, swimming depth and distance to the river outlet}

A striking feature of the tracking data was that most fish migrated towards the Etne River outlet and stayed within a relatively short distance of this outlet for a long period (about 6 wk) after release; this 
included fish that actually entered the river. After this time period, the fish increased their use of habitats further out in the fjord. This behavioural change could indicate that some of the fish recovered from salmon lice infestation. These findings and interpretations are consistent with Birkeland (1996) and Birkeland \& Jakobsen (1997) who observed premature returns of infected fish migrating back to the sea after a median period of $38 \mathrm{~d}(\sim 6 \mathrm{wk})$ in the river, having recovered from the salmon lice infection. The sea trout in the present study appeared to travel less far from the river and use the inner fjord area more extensively than reported from other tracking studies on sea trout where high lice infection has not been an issue (Dieperink et al. 2001, Thorstad et al. 2004, Rikardsen et al. 2007, Thorstad et al. 2007, Middlemas et al. 2009). This is another indication that the habitat use of the sea trout in this study was affected by the high lice infection pressure.

The swimming depth of tracked sea trout was negatively correlated with the initial salmon lice infestation, indicating a behaviour influenced by the infestation level and a preference for lower salinities in highly infested sea trout. Salmon lice display positive phototaxis and migrate towards the surface, but also avoid low salinities (Heuch 1995) where lice mortality is higher and the infection ability of lice is compromised (Bricknell et al. 2006, Connors et al. 2008). Hence, salmon lice may concentrate and cause a particularly strong infection pressure in the lower part of the halocline (Heuch 1995), a depth zone frequently occupied by sea trout as shown in this and other studies (e.g. Rikardsen et al. 2007). Salinity modelling and CTD-profiles with detailed temporal and spatial distributions from the Etnefjord in 2009 and 2013 indicate that the salinity in surface waters above $0.5-1 \mathrm{~m}$ depth is mostly $<20 \mathrm{ppt}$, and frequently far below. In the inner bay, salinities $<20 \mathrm{ppt}$ extend down to $2 \mathrm{~m}$ depth. The reduced salinity surface water layer generally extends deepest close to the Etne River outlet, although the temporal variation there may be relatively large (Lars Asplin, IMR, Bergen, Norway, pers. comm.). In accordance with this, the tagged fish remained in shallower water further out in the fjord as compared to close to the river outlet. The more surface-oriented behaviour in highly infested sea trout can thus be interpreted as a behaviour for reducing infestation. This is noteworthy, as swimming closer to the surface may represent yet another trade-off for the sea trout, i.e. between parasite avoidance and predation risk, due to increased exposure to predatory birds (Ward \& Hvidsten 2011). We expected, but did not find, a treatment effect. This could be related to a limited statistical power and a high spatio-temporal variation, combined with the fact that the fish were already infected at the time of treatment and a moderate treatment effect (see 'Treatment effects on infestation' below).

\section{Fate of tracked individuals}

The predation events occurred both relatively close to the river outlet and further away (from 365 to $3478 \mathrm{~m}$ ), but over time the fish that suffered predation stayed further away from the river outlet than the surviving fish. From the salinity tolerance of salmon lice, the distance to salmon farms and modelling work on salmon lice dispersal in the Hardangerfjord area (Asplin et al. 2014), we can infer that infection pressure was higher further out in the fjord than in the inner bay. The fish that suffered predation therefore likely acquired higher infestations than the survivors. They could therefore be more susceptible to predators since salmon lice infection may reduce burst swimming performance and predator vigilance (Wagner et al. 2008, Krkošek et al. 2011). An overall survival of $>50 \%$ for the tracked sea trout and the relatively low mortality rate estimates $\left(0.32 \% \mathrm{~d}^{-1}\right)$, combined with the larger distance to the river outlet in the predated fish, indicated that staying relatively close to the river outlet enhanced survival. On the other hand, mortality may be expected to be highest during the first $14 \mathrm{~d}$ after sea entrance and higher in small fish (Dieperink et al. 2001, Middlemas et al. 2009). Since we tagged sea trout that were already in the fjord and sizes somewhat larger than the typical sea trout smolt size $(14-20 \mathrm{~cm})$, the observed mortality in the present study was likely an underestimate of the total sea phase mortality from river descent in spring to ascent in autumn.

\section{Treatment effects on infestation}

The reduced infestation in both treatment and control fish in the cage experiment stands in contrast to the development of high infestation intensity observed in wild fish sampled in the National Salmon Lice Monitoring Program (Bjørn et al. 2012). The EB treatment effect on infestation was statistically significant; however, we consider the $32 \%$ stronger reduction due to treatment to be a moderate treatment effect. Reduced sensitivity to EB could potentially be an issue (Igboeli et al. 2012), but the skin concentration of EB was much higher than the level typically 
obtained by oral administration (Skilbrei et al. 2008). The treatment efficacy (sensu Stone et al. 2000) of $42.7 \%$ observed in the present study was also within the ranges of $30-60 \%$ that could be expected after a week of oral treatment (Stone et al. 1999, 2000). The salinity was not measured at the experiment cage location, but as discussed above (in 'Infestation, swimming depth and distance to the river outlet'), we can reasonably assume that there was a low-salinity layer extending at least 1-2 m downwards. As the net pen used for caging was only $1.5 \mathrm{~m}$ deep, it is therefore highly likely that the caged fish experienced reduced salinities. Salmon louse survival decreases with decreasing salinity (Wells et al. 2007, Connors et al. 2008), and salmon louse copepodites actively avoid salinities $<20-27$ ppt (Heuch 1995, Bricknell et al. 2006). The low copepodite infestation at the end of the experiment indicated that there was no or very little new recruitment of salmon lice during the sea cage experiment period. Thus, the reduced intensity observed in the control group may have been caused by natural mortality of the salmon louse (Wagner et al. 2008), while there was an additional mortality in the EB treatment group. If we are right in our contention that the caged fish were held at low salinity, this would mean that the salmon lice on treated fish were stressed by both reduced salinity and EB toxicity. It would also imply that for fish in high-salinity waters, the effect of EB could be less than that estimated in this study since the lice would be less impeded by osmoregulatory stress.

There was a relatively high mortality in the fish cage experiment, with higher mortality associated with high infestation of motile lice stages, as could be expected from earlier works (Bjørn \& Finstad 1997, Finstad et al. 2000). The high mean cage fish infestation was in a clinical range ( $>0.75$ lice $\mathrm{g}^{-1}$ ) that is well-known to initiate morbidity and death (Wagner et al. 2008), and all the fish that died in the cage experiment had infections above this threshold. Based on previous experience with the use of high doses of EB in the laboratory (Roy et al. 2000, Glover et al. 2010, Poley et al. 2013) and field experiments (Skilbrei et al. 2013) we infer that it is not very likely that the dose applied in the present study was the cause of death for 4 of the treated individuals.

\section{Treatment effects on tracked individuals}

We detected no behavioural difference between treatment groups during the tracking of sea trout, nor did we find any treatment effect on the mortality of the tracked fish. These results are in contrast to findings by other authors. For example, Birkeland \& Jakobsen (1997) found that sea trout that were experimentally exposed to salmon lice before release into the sea returned to freshwater much faster than the control (unexposed) fish. Other studies have found a positive effect of parasiticide treatment on the sea survival of salmon and anadromous brown trout (Krkošek et al. 2013, Skilbrei et al. 2013, Skaala et al. 2014). However, these studies exposed uninfested fish to salmon lice at the start of the experiment, whereas in our study the fish had already acquired significant amounts of chalimus and motile stages of salmon lice at the start of the experiment. This might have masked any treatment effect, in particular since our cage experiment showed a moderate effect on infestation levels. The lice infestation levels above or close to the 0.1 lice $^{-1}$ threshold for physiological impact (Wagner et al. 2008) before EB treatment indicate that the tracked sea trout may have been physically and physiologically affected by salmon lice infestation before the treatment had any detrimental effect on the attached salmon lice. Infection with salmon lice rapidly elicits stress, immune responses and skin damage in the affected fish (Bjørn \& Finstad 1998, Finstad et al. 2000, Fast et al. 2006), and even a low number (10 or less) of preadult and adult lice have been shown to result in stress responses that can last for a long time (Nolan et al. 1999). Thus, high initial infestations combined with high infection pressure during the experiment may have caused behavioural responses in most tagged fish, whether treated or not. It should be emphasized that our contrast between a treatment and control group could capture an EB treatment effect, but not the effect of salmon lice infestation per se. We must also acknowledge that the statistical power of our sample size was limited, a limitation further constrained by the significant differences in tag expulsion rate between the treatment groups. The reason for this difference remains unclear, but it could be related to the abdominal EB treatment eliciting a stronger immune response to the abdominal tag implant.

\section{CONCLUSION}

We found several indications that sea trout behaviour was modified by the high salmon lice infection pressure. The sea trout moved less far from the river outlet than has been observed in other studies. Many sea trout stayed for a $\sim 6$ wk period very close to the river outlet, a behaviour mimicking the 'de-licing' be- 
haviour described for sea trout that return prematurely to the river. The fish that were lost to predation stayed further away from the river, which could imply that they had acquired high infestations prior to the predation event. Finally, heavily infected sea trout stayed closer to the surface, indicating that they chose less saline water. Spending time in the river and river outlet at a time when the trout would normally be foraging at sea reduces their growth potential. As salmon lice infection pressure is influenced by salmon farming practice, regulation of this practice may have implications for behaviour and growth of wild sea trout, mediated through interactions between salmon lice and sea trout. Although salmon lice prophylaxis has been documented to have a positive effect on sea trout survival in other studies, we did not find effects of the treatment on sea trout behaviour. We suggest that this was caused by sea trout responses to lice infection both in treated and untreated fish, rather than by a lack of behavioural response to the salmon lice infestation.

Acknowledgements. The Norwegian Research Council (project no. 221404), the Institute of Marine Research, the Norwegian Institute for Nature Research (Strategic Institute Programme, project no. 160022/F40), and the Norwegian Food Safety Authority funded this project. We thank Vidar Børretzen, Gerd Stølås and Bernt Ramsvik for aid during the fieldwork, and Elina Halttunen for thoughtful input to the manuscript. We thank 3 anonymous referees for providing insightful and constructive comments and suggestions for the manuscript. The experiment described was approved by the local responsible laboratory animal science specialist under the surveillance of the Norwegian Animal Research Authority (NARA) and registered by the Authority (FOTS ID 4351).

\section{LITERATURE CITED}

Aas Ø, Klemetsen A, Einum S, Skurdal J (eds) (2011) Atlantic salmon ecology. Wiley-Blackwell, Chichester

Anonymous (2009) Bestandsutvikling hos sjøørret og forslag til forvaltningstiltak. The Norwegian Directorate for Nature Management, Trondheim (in Norwegian)

Asplin L, Boxaspen KK, Sandvik AD (2011) Modeling the distribution and abundance of planktonic larval stages of Lepeophtheirus salmonis in Norway. In: Jones SRM, Beamish RJ (eds) Salmon lice: an integrated approach to understanding parasite abundance and distribution. Wiley-Blackwell, Chichester, p 29-50

Asplin L, Johnsen IA, Sandvik AD, Albretsen J, Sundfjord V, Aure J, Boxaspen KK (2014) Dispersion of salmon lice in the Hardangerfjord. Mar Biol Res 10:216-225

> Birkeland K (1996) Consequences of premature return by sea trout (Salmo trutta) infested with the salmon louse (Lepeophtheirus salmonis Krøyer): migration, growth, and mortality. Can J Fish Aquat Sci 53:2808-2813

Birkeland K, Jakobsen P (1997) Salmon lice, Lepeophtheirus salmonis, infestation as a causal agent of premature return to rivers and estuaries by sea trout, Salmo trutta, juveniles. Environ Biol Fishes 49:129-137

Bjørn PA, Finstad B (1997) The physiological effects of salmon lice infection on sea trout post smolts. Nord J Freshw Res 73:60-72

Bjørn PA, Finstad B (1998) The development of salmon lice (Lepeophtheirus salmonis) on artificially infected post smolts of sea trout (Salmo trutta). Can J Zool 76:970-977

> Bjørn PA, Finstad B, Kristoffersen R (2001) Salmon lice infection of wild sea trout and Arctic char in marine and freshwaters: the effects of salmon farms. Aquacult Res 32: 947-962

Bjørn PA, Nilsen R, Llinares RMS, Asplin L and others (2012) Lakselusinfeksjonen på vill laksefisk langs norskekysten i 2012. Institute of Marine Research, Bergen (in Norwegian)

> Boxaspen K (2006) A review of the biology and genetics of sea lice. ICES J Mar Sci 63:1304-1316

> Bricknell IR, Dalesman SJ, O'Shea B, Pert CC, Mordue Luntz AJ (2006) Effect of environmental salinity on sea lice Lepeophtheirus salmonis settlement success. Dis Aquat Org 71:201-212

Burka JF, Fast MD, Revie CW (2012) Lepeophtheirus salmonis and Caligus rogercresseyi. In: Woo PTK, Buchmann K (eds) Fish parasites: pathobiology and protection. CABI Publisher, Wallingford, p 350-370

> Connors BM, Juarez-Colunga E, Dill LM (2008) Effects of varying salinities on Lepeophtheirus salmonis survival on juvenile pink and chum salmon. J Fish Biol 72: 1825-1830

> Costello MJ (2006) Ecology of sea lice parasitic on farmed and wild fish. Trends Parasitol 22:475-483

Crawley MJ (2013) The R book. John Wiley \& Sons, Chichester

Dieperink C, Pedersen S, Pedersen MI (2001) Estuarine predation on radiotagged wild and domesticated sea trout (Salmo trutta L.) smolts. Ecol Freshw Fish 10:177-183

Elliott JM (1994) Quantitative ecology and the brown trout. Oxford University Press, Oxford

- Fast MD, Muise DM, Easy RE, Ross NW, Johnson SC (2006) The effects of Lepeophtheirus salmonis infections on the stress response and immunological status of Atlantic salmon (Salmo salar). Fish Shellfish Immunol 21:228-241

Finstad B, Bjørn PA (2011) Present status and implications of salmon lice on wild salmonids in Norwegian coastal zones. In: Jones SRM, Beamish RJ (eds) Salmon lice: an integrated approach to understanding parasite abundance and distribution. Wiley-Blackwell, Chichester, p 279-305

Finstad B, Bjørn PA, Grimnes A, Hvidsten NA (2000) Laboratory and field investigations of salmon lice [Lepeophtheirus salmonis (Krøyer)] infestation on Atlantic salmon (Salmo salar L.) post-smolts. Aquacult Res 31:795-803

Finstad B, Ulvan EM, Jonsson B, Ugedal O and others (2011) Suggestions for sea trout monitoring in Norway. Norwegian Institute for Nature Research, Trondheim

Fjørtoft HB, Borgstrøm R, Skaala Ø (2014) Differential changes in growth patterns of anadromous brown trout and Atlantic salmon from the River Etneelva over a 25year period. Mar Biol Res 10:301-307

> Gjelland KØ, Hedger RD (2013) Environmental influence on transmitter detection probability in biotelemetry: developing a general model of acoustic transmission. Methods Ecol Evol 4:665-674

Gjerde B, Odegard J, Thorland I (2011) Estimates of genetic 
variation in the susceptibility of Atlantic salmon (Salmo salar) to the salmon louse Lepeophtheirus salmonis. Aquaculture 314:66-72

Glover KA, Samuelsen OB, Skilbrei OT, Boxaspen K, Lunestad BT (2010) Pharmacokinetics of emamectin benzoate administered to Atlantic salmon, Salmo salar L., by intraperitoneal injection. J Fish Dis 33:183-186

> Hamre LA, Eichner C, Caipang CMA, Dalvin ST and others (2013) The salmon louse Lepeophtheirus salmonis (Copepoda: Caligidae) life cycle has only two chalimus stages. PLoS ONE 8:e73539

> Heuch PA (1995) Experimental evidence for aggregation of salmon louse copepodids (Lepeophtheirus salmonis) in step salinity gradients. J Mar Biol Assoc UK 75:927-939

> Heuch PA, Nordhagen JR, Schram TA (2000) Egg production in the salmon louse [Lepeophtheirus salmonis (Krøyer)] in relation to origin and water temperature. Aquacult Res 31:805-814

Igboeli OO, Fast MD, Heumann J, Burka JF (2012) Role of Pglycoprotein in emamectin benzoate (SLICE®) resistance in sea lice, Lepeophtheirus salmonis. Aquaculture 344-349:40-47

> Jonsson B, Jonsson N (2009) Migratory timing, marine survival and growth of anadromous brown trout Salmo trutta in the River Imsa, Norway. J Fish Biol 74:621-638

Krkošek M, Connors BM, Ford H, Peacock S and others (2011) Fish farms, parasites, and predators: implications for salmon population dynamics. Ecol Appl 21:897-914

Krkošek M, Revie CW, Gargan PG, Skilbrei OT, Finstad B, Todd CD (2013) Impact of parasites on salmon recruitment in the Northeast Atlantic Ocean. Proc R Soc Lond B Biol Sci 280:20122359

> Middlemas SJ, Stewart DC, Mackay S, Armstrong JD (2009) Habitat use and dispersal of post-smolt sea trout Salmo trutta in a Scottish sea loch system. J Fish Biol 74: 639-651

- Nolan DT, Reilly P, Bonga SEW (1999) Infection with low numbers of the sea louse Lepeophtheirus salmonis induces stress-related effects in postsmolt Atlantic salmon (Salmo salar). Can J Fish Aquat Sci 56:947-959

Pinheiro J, Bates D, DebRoy S, Sarkar D, the R Core Team (2013) nlme: linear and nonlinear mixed effects models. $\mathrm{R}$ package version 3.1-111. http://CRAN.R-project.org/ package $=$ nlme

Poley J, Purcell SL, Igboeli OO, Donkin A, Wotton H, Fast MD (2013) Combinatorial effects of administration of immunostimulatory compounds in feed and follow-up administration of triple-dose SLICE® (emamectin benzoate) on Atlantic salmon, Salmo salar L., infection with Lepeophtheirus salmonis. J Fish Dis 36:299-309

R Development Core Team (2013) R: a language and environment for statistical computing. $\mathrm{R}$ Foundation for Statistical Computing, Vienna. www.r-project.org

Rikardsen AH, Diserud OH, Elliott JM, Dempson JB, Sturlaugsson J, Jensen AJ (2007) The marine temperature and depth preferences of Arctic charr (Salvelinus alpinus) and sea trout (Salmo trutta), as recorded by data storage tags. Fish Oceanogr 16:436-447

Roy WJ, Sutherland IH, Rodger HDM, Varma KJ (2000) Tolerance of Atlantic salmon, Salmo salar L., and rainbow trout, Oncorhynchus mykiss (Walbaum), to emamectin benzoate, a new orally administered treatment for sea lice. Aquaculture 184:19-29

Editorial responsibility: Kenneth Black, Oban, UK
Schielzeth H (2010) Simple means to improve the interpretability of regression coefficients. Methods Ecol Evol $1: 103-113$

Serra-Llinares RM, Bjørn PA, Finstad B, Nilsen R, Harbitz A, Berg M, Asplin L (2014) Salmon lice infection on wild salmonids in marine protected areas: an evaluation of the Norwegian 'National Salmon Fjords'. Aquacult Environ Interact 5:1-16

Skaala Ø, Kålås S, Borgstrøm R (2014) Evidence of salmon lice-induced mortality of anadromous brown trout (Salmo trutta) in the Hardangerfjord, Norway. Mar Biol Res 10: 279-288

Skilbrei OT, Glover KA, Samuelsen OB, Lunestad BT (2008) A laboratory study to evaluate the use of emamectin benzoate in the control of sea lice in sea-ranched Atlantic salmon (Salmo salar L.). Aquaculture 285:2-7

> Skilbrei OT, Finstad B, Urdal K, Bakke G, Kroglund F, Strand R (2013) Impact of early salmon louse, Lepeophtheirus salmonis, infestation and differences in survival and marine growth of sea-ranched Atlantic salmon, Salmo salar L., smolts 1997-2009. J Fish Dis 36:249-260

> Stone J, Sutherland IH, Sommerville CS, Richards RH, Varma KJ (1999) The efficacy of emamectin benzoate as an oral treatment of sea lice, Lepeophtheirus salmonis (Krøyer), infestations in Atlantic salmon, Salmo salar L. J Fish Dis 22:261-270

Stone J, Sutherland IH, Sommerville C, Richards RH, Varma KJ (2000) Field trials to evaluate the efficacy of emamectin benzoate in the control of sea lice, Lepeophtheirus salmonis (Krøyer) and Caligus elongatus Nordmann, infestations in Atlantic salmon Salmo salar L. Aquaculture 186:205-219

Therneau TM (2000) Modeling survival data: extending the Cox model. Springer, New York, NY

Therneau TM (2013) A package for survival analysis in S. $\mathrm{R}$ package version 2.37-4. http://CRAN.R-project.org/ package=survival

> Thorstad EB, Okland F, Finstad B, Sivertsgard R, Bjørn PA, McKinley RS (2004) Migration speeds and orientation of Atlantic salmon and sea trout post-smolts in a Norwegian fjord system. Environ Biol Fishes 71:305-311

> Thorstad EB, Okland F, Finstad B, Sivertsgard R, Plantalech N, Bjørn PA, McKinley RS (2007) Fjord migration and survival of wild and hatchery-reared Atlantic salmon and wild brown trout post-smolts. Hydrobiologia 582:99-107

Wagner GN, Fast MD, Johnson SC (2008) Physiology and immunology of Lepeophtheirus salmonis infections of salmonids. Trends Parasitol 24:176-183

Ward DM, Hvidsten NA (2011) Predation: compensation and context dependence. In: Aas $\varnothing$, Klemetsen A, Einum S, Skurdal J (eds) Atlantic salmon ecology. Wiley-Blackwell, Chichester, p 199-220

- Wells A, Grierson CE, Marshall L, MacKenzie M and others (2007) Physiological consequences of 'premature freshwater return' for wild sea-run brown trout (Salmo trutta) postsmolts infested with sea lice (Lepeophtheirus salmonis). Can J Fish Aquat Sci 64:1360-1369

> Werner EE, Gilliam JF (1984) The ontogenetic niche and species interactions in size-structured populations. Annu Rev Ecol Evol Syst 15:393-425

> Wood SN (2011) Fast stable restricted maximum likelihood and marginal likelihood estimation of semiparametric generalized linear models. J R Stat Soc B 73:3-36

Submitted: January 27, 2014; Accepted: April 17, 2014

Proofs received from author(s): June 2, 2014 